\title{
A rede da CEFNOB e o território: breves considerações sobre o desenvolvimento urbano no município de Campo Grande, MS
}

\author{
The network CEFNOB and territory: brief considerations on urban development in \\ the city of Campo Grande, MS
}

\section{Le CEFNOB réseau et territoire: brèves considérations sur le développement urbain dans la ville de Campo Grande, MS}
El CEFNOB red y el territorio: breves consideraciones sobre el desarrollo urbano en la ciudad de Campo Grande, MS

\author{
Gleicy Denise Vasques Moreira Santos* \\ (gleicysantos@unipampa.edu.br)
}

Recebido em 30/03/2013; revisado e aprovado em 23/08/2013; aceito em 16/11/2013

\begin{abstract}
Resumo: O artigo apresenta uma reflexão sobre o papel e o significado da Companhia Estrada de Ferro Noroeste do Brasil (CEFNOB) em sua extensão do território paulista ao território sul-mato-grossense, enquanto processo de indução ao desenvolvimento da região centro-oeste. Destaca-se o papel das redes técnicas em sua interação com o território e suas implicações institucionais. A capital do Estado, Campo Grande, é analisada nesse contexto. Palavras-chave: Rede técnica. Território. Desenvolvimento urbano.

Abstract: The paper presents a reflection on the role and significance of the Railroad Company Northwest Brazil (CEFNOB) in its extension of the state territory to the territory of South Mato Grosso, while induction process to the development of the Midwest. We highlight the role of technical networks in their interaction with the territory and its institutional implications. The state capital, Campo Grande, is analyzed in this context.

Key words: Network technique. Territory. Urban development.

Résumé: Cet article présente une réflexion sur le rôle et l'importance du chemin de fer Northwest Company Brésil (CEFNOB) dans son extension du territoire de l'Etat sur le territoire de Mato Grosso du Sud, tandis que processus d'induction pour le développement du Midwest. Nous soulignons le rôle des réseaux techniques dans leur interaction avec le territoire et ses implications institutionnelles. La capitale de l'Etat, Campo Grande, est analysée dans ce contexte.

Mots-clés: Technique de réseau. Territoire. Le développement urbain.

Resumen: El artículo presenta una reflexión sobre el papel y la importancia de la Compañía del Ferrocarril Noroeste de Brasil (CEFNOB) en su extensión del territorio del Estado en el territorio de Mato Grosso del Sur, mientras que el proceso de inducción al desarrollo de la región central. Destacamos el papel de las redes técnicas en su interacción con el territorio y sus implicaciones institucionales. La capital del estado, Campo Grande, se analiza en este contexto. Palabras clave: Técnica de red. Territorio. El desarrollo urbano.
\end{abstract}

\section{Introdução}

O presente trabalho tem como objetivo analisar e compreender o recente processo de desenvolvimento urbano, vivenciado no município de Campo Grande, capital do Estado de Mato Grosso do Sul. Para tanto utilizamos como suporte em nossa reflexão conceitos e temas relacionados ao Desenvolvimento Urbano, como a formação de redes técnicas, a globalização, e seus reflexos no território e na rede urbana.

Além disso, analisamos o significado e o papel da técnica em relação ao desenvolvimento social e econômico. Para tanto, partimos de uma reflexão crítica sobre a ideia de impacto tecnológico presente na assertiva do papel estruturante das redes técnicas em sua relação com o território, trazendo à tona o caso da Companhia Estrada de Ferro Noroeste do Brasil (CEFNOB).

Tendo em vista os efeitos e as determinações do processo de globalização da economia, quanto à produção e estruturação do espaço geográfico, analisamos a relação existente entre a funcionalidade das redes técnicas e a institucionalidade dos territórios.

Como objetivos específicos do presente trabalho, temos: (1) discutir a formação das redes e sua interação com o território; (2) observar o processo de globalização e os seus impactos sobre as redes urbanas; (3)

\footnotetext{
* Universidade de Santa Cruz do Sul (UNISC) e Universidade Federal do Pampa (UNIPAMPA), Rio Grande do Sul, Brasil.
} 
apresentar algumas considerações sobre a dinâmica recente da rede urbana brasileira; (4) analisar a construção da CEFNOB e a dinâmica do desenvolvimento urbano de Campo Grande, capital do Estado de Mato Grosso do Sul.

Com isso, busca-se a compreensão e a utilização de ferramentas conceituais e metodológicas que possam ser úteis na compreensão das mudanças recentes, a partir do entendimento de que a rede é uma construção social, resultado de uma série de processos, que em si são conflituosos.

\section{A formação das redes e sua interação com o território}

Muitas são as representações que as redes vêm assumindo na área de estudo das Ciências Humanas, no entanto, cabe aqui um recorte acerca da contribuição da Geografia ao analisar como a relação entre redes técnicas e território se inscreve nesse debate, principalmente diante da intensificação do processo de globalização e seus impactos sobre o espaço geográfico.

Ao buscar a participação nesse debate, entende-se que, enquanto a técnica explicita regras do modo de ação prática do como fazer, a tecnologia representa uma espécie de teorização das técnicas, no sentido de constituir um procedimento lógico que possibilita compreender a ordem e a racionalidade presente em uma ou na articulação de mais técnicas.

Considera-se que a técnica e a tecnologia, são resultados da ação humana e dessa forma, devem ser pensadas no contexto das relações sociais e no âmbito de seu desenvolvimento histórico. As técnicas expressam, por meio dos objetos técnicos, seu conteúdo histórico e, em cada momento de sua existência, da sua criação à sua instalação e operação, revelam a combinação, em cada lugar, das condições políticas, econômicas, sociais, culturais e geográficas que permitem seu aproveitamento. Um desses objetos técnicos é a rede, de acordo com Silveira (2003).

A noção de rede é, portanto, também social e política, tendo vem vista pessoas, mensagens, valores que a frequentam e com isso estabelecem relações de cooperação e de antagonismo que estão presentes na sociedade humana, para Santos (1996).
Nesse aspecto, a análise da evolução das redes, distinguindo sua infraestrutura, seus serviços e seu comando, permite-nos superar essa contradição evidenciando que sua participação é essencial para a construção de novas escalas territoriais, ainda que seu papel não seja determinante, mas de acompanhamento, na estruturação dos territórios, conforme Silveira (2003).

A partir disso, compreende-se que o território não se restringe apenas à escala nacional, representada pelo Estado, sua categoria gestora e que expressa uma construção e/ou uma desconstrução, nas mais diversas escalas, tanto espaciais como temporais. A partir disso, cabe a análise do impacto tecnológico, especialmente no atual estágio de desenvolvimento das forças de produção capitalista, tendo em vista uma presença crescente da tecnologia no contexto das relações sociais e econômicas.

Deve-se pensar a rede técnica como um elemento que abre um horizonte de possibilidades em relação ao desenvolvimento de um dado território. A instalação e o aproveitamento das redes técnicas, engendrados por uma dada dinâmica social e econômica, e expressão de relações de poder existentes no lugar, torna aparente tanto as potencialidades como os constrangimentos ao desenvolvimento social e espacial no território.

Pode-se, então, capturar a fundamental importância das reflexões quanto aos "efeitos" e às "determinações" do processo de globalização da economia e sua interface com as redes na produção e organização do "território em particular".

No atual contexto da economia globalizada, as mudanças no padrão tecnológico e produtivo se fazem acompanhar da emergência de novas formas espaciais, ou de velhas formas espaciais com novos conteúdos, e de uma nova lógica espacial onde, a priori, o espaço dos fluxos tende a sobrepor-se ao espaço dos lugares. O lugar redefine-se a partir do potencial integrativo do novo padrão tecnológico, ganhando em densidade comunicacional, informacional e técnica no âmbito das redes informacionais que se estabelecem em escala planetária, nesse sentido, Santos (1996) e Silveira (2003).

Observa-se que se insere no contexto da divisão tradicional do trabalho, uma nova divisão do trabalho. Esta é resultante dos 
vetores da modernidade e da regulação, o que nos permite considerar, conforme Harvey (1992), a existência da reafirmação da dimensão espacial, tendo em vista que se acentua a importância conferida à diferenciação concreta entre os distintos espaços geográficos, pois é neles que a globalização se expressa concretamente e assume especificidades.

Além disso, essa interdependência possibilitada pelas redes é de origem econômica e política. Isso porque, enquanto instrumentos de intermediação, de intercâmbio, as redes são fundadas no coração das operações de mercado. Assim o território onde elas se instalam informa seu conteúdo econômico e político, na medida em que a configuração espacial das redes técnicas resulta do embate político entre Estado e mercado. Nesse embate, o poder público geralmente é chamado a prover o conjunto de infraestruturas que facilitem e assegurem as melhores condições para o desenvolvimento das atividades do mercado, com base em Silveira (2003).

Dessa forma, pode-se considerar que devemos ir além dos mitos recorrentes das relações deterministas entre redes e sociedade, e entre redes e territórios, ou seja, nosso olhar deve atentar para um sistema, que interage com a urbanização, com a divisão territorial do trabalho e com a diferenciação crescente provocada em nações, regiões e cidades, tendo em vista de um lado, a racionalidade econômica e de outro, as estratégias de atores com muitos e distintos interesses territoriais.

Com o extraordinário desenvolvimento das redes de transporte e telecomunicação, durante a segunda metade do século XX, difundiram-se as teses que superestimam $o$ poder das mudanças técnicas; no centro desse debate está evidenciado um viés determinista, para Dias (2005, p. 15):

Desde então, a rede não é mais somente observada sobre o corpo humano - como malha ou tecido -, ou no seu interior. Ela pode ser objetivada como matriz técnica infraestrutura rodoviária, estrada de ferro, telegrafia, modificando a relação com o espaço e com o tempo. Se até aquele momento a história da rede esteve ligada a uma referência ao organismo a seguir ela estará também ligada a uma referência à técnica.

Ressalta-se que as relações entre as redes e os territórios são muito mais complexas do que defendem as teses deterministas. Para
Dias (2005, p. 22), devemos nos atentar para as limitações em torno de duas teses amplamente difundidas:

A primeira associa contração das distâncias à negação do espaço, reduzindo o espaço geográfico à noção de distância; a segunda postula que os efeitos do desenvolvimento técnico seriam instantâneos e as técnicas se desenvolveriam num espaço ausente de história, reduzindo assim o tempo à noção de tempo real. Pensamos que, ao contrário, vivemos mergulhados numa multiplicidade de tempos sociais, como já assinalava G. Gurvitch no século passado - "tempos diferentes próprios às civilizações, nações, tipos de sociedades e grupos variados".

Compreende-se, portanto, que o foco está em desenvolver ferramentas conceituais e metodológicas que valorizem a compreensão da natureza das mudanças em curso, tendo em vista que a rede é uma construção histórica e social, resultado de uma série de processos, que em si são conflituosos.

\section{A globalização e os seus impactos sobre as redes urbanas}

O processo de globalização pode ser compreendido dentro do próprio sistema mundial capitalista a partir dos grandes descobrimentos, da revolução industrial e das ondas sucessivas de expansão do capital e sua internacionalização. Porém, como é mais comumente abordada, a globalização surgiu como um novo momento decorrente, entre outros, da crise do padrão Bretton Woods, com a desregulamentação do sistema financeiro internacional, que também impulsionou uma Terceira Revolução Industrial, com uma nova divisão internacional do trabalho, a partir de meados da década de 1970.

Nesse sentido, Souza (2006, p. 123) aborda o processo na seguinte perspectiva:

Argumentam, tipicamente, que o Estadonação teria se tornado "pequeno demais" em face do grande capital transnacional, ao passo que, para a promoção ágil do desenvolvimento econômico e do bem-estar dos cidadãos, mostrar-se-ia "grande demais". Para eles, uma cidade deveria funcionar tal qual uma empresa, concorrendo com outras cidades para atrair capitais, cabendo ao Estado o papel de costurar "consensos" e ajudar a criar um bom "ambiente de negócios". 
O autor destaca que nesse contexto de globalização, o Estado assume para muitos autores um papel em termos de políticas públicas, no intuito de potencializar a cidade no contexto do desenvolvimento econômico.

Dentro dessa análise, cabe observar que o aparelho de Estado assumiria assim um papel de fiador ao status quo capitalista e, numa esfera menor, enquanto governo específico como na escala local, poderia se mostrar permeável às pressões e demandas populares e promover políticas públicas e iniciativas que não sejam liberticidas.

Com respaldo em Souza (2006, p. 128129), pode-se compreender a visão de alguns autores sob a abordagem do "empresarialismo urbano":

[...] argumentam, tipicamente, que, debilitado, o Estado-nação ter-se-ia tornado "pequeno demais" em face do grande capital transnacional, ao passo que, para a promoção ágil do desenvolvimento econômico e do bem-estar dos cidadãos, mostrar-se-ia "grande demais". Para os "empresarialistas urbanos", uma cidade deveria funcionar tal qual uma empresa, concorrendo com outras cidades para atrair capitais, na base da construção de uma "governança" (Estado e sociedade civil) eficiente e moderna.

Com base nas considerações acima, observa-se que, para os empresarialistas urbanos, ao Estado local está reservado o papel de costurar "pactos" e "consensos" locais, contribuindo dessa forma como facilitador de um "ambiente de negócios", o que garantiria a projeção da imagem da cidade no país e no mundo. Destaca-se, dentro dessa concepção, que a tarefa política para os gestores urbanos focalizar-se-ia no fortalecimento da competitividade local, o que contribuiria para a formação de redes de governos locais e regionais.

A partir de outra compreensão, Souza (2006, p. 131) destaca:

Uma interpretação concorrente, notadamente no Brasil, é a representada pelo ideário da reforma urbana. Aqueles que com esta posição se identificam tendem a assumir uma postura cética e crítica em face da globalização capitalista. Recusam a atração de investimentos a qualquer preço, priorizando a meta da redução de desigualdades.

Pelo contrário, ressaltam o papel fundamental a ser desempenhado pelo Estado na redução de disparidades - as quais tende- riam, na esteira da globalização, inclusive a recrudescer.

Pode-se dizer que a meta da redução de desigualdades, por meio da intervenção estatal é a principal defesa dessa concepção teórica, que destaca também que o desenvolvimento socioespacial, a reforma urbana, é uma espécie de equivalente urbano da reforma agrária.

Destacando uma das várias facetas da globalização, pode-se dizer que, especialmente após a Segunda Guerra Mundial, ela se manifesta pelo espraiamento do capital produtivo oriundo de grandes corporações e que leva o Estado a atuar como um importante centro de gestão do território, tendo em vista os ciclos de reprodução do capital.

Nesse sentido, Corrêa (2006, p. 255) pondera:

Os investimentos, pensados e programados segundo uma perspectiva global, criaram e reestruturaram inúmeras e complexas redes geográficas das quais a rede urbana é a expressão mais contundente. Trata-se, em toda parte, de uma rede urbana impactada pela globalização, na qual cada centro, por minúsculo que seja, participa, ainda que não exclusivamente, de um ou mais circuitos espaciais de produção (Santos, 1988), produzindo, distribuindo ou apenas consumindo bens, serviços e informações que, crescentemente, circulam por meio da efetiva ação de corporações globais.

A rede urbana é afetada pela globalização tanto por meio de criações urbanas recentes, em relação às quais o Brasil constitui-se em excelente laboratório para estudos, como da refuncionalização dos centros preexistentes, imposta ou induzida pelas corporações globais.

Do texto em destaque observa-se que, para o referido autor, as relações entre rede urbana e corporações globais são complexas e não estão definitivamente postas, o que o leva a considerar os possíveis efeitos da globalização sobre a rede urbana. Em outras palavras, os recursos exógenos advindos da captação de recursos externos, decorrentes da disputa global pela implantação de empresas e novas tecnologias geram efeitos sobre o sistema urbano, como a transformação espacial e funcional entre as diferentes áreas da cidade e redes de cidades.

No caso brasileiro, observaram-se no último quartel do século XX novos núcleos de povoamento em áreas de fronteira de 
ocupação e fronteira de modernização, todos decorrentes da globalização, em unidades federadas, como: Mato Grosso, Rondônia, Tocantins, Pará, Roraima, Mato Grosso do Sul e Bahia, os quais caracterizaram um processo de refuncionalização desses centros.

Ainda segundo Corrêa (2006, p. 264-267):

A segunda possibilidade diz respeito à transformação do pequeno núcleo a partir de novas atividades, induzidas de fora ou criadas internamente, que conferem uma especialização produtiva ao núcleo preexistente, inserindo-o diferentemente na rede urbana, introduzindo nela uma mais complexa divisão territorial do trabalho.

Pode-se dizer que a própria descoberta de novas especializações produtivas, vão permitir aos núcleos urbanos um novo papel, uma singularidade funcional, compreendidas como uma diferenciação no âmbito da economia global e de integração a esta mesma economia.

Compreende-se que as especializações produtivas podem estar associadas às atividades agrícolas regionais que avançam para atividades industriais criadas no bojo da expansão do capital produtivo por meio de filiais, ou podem ser criações das elites locais que necessitam encontrar outras atividades que lhes permitam manter-se como tais.

\section{Considerações sobre a dinâmica recente da rede urbana brasileira}

Para a economia brasileira, o período que compreende a metade final do séc. XIX e o início do XX apresenta transformações importantes, como a exportação, geradora principal da renda nacional, que se concentrava regionalmente sobre um produto de mais elevada rentabilidade, tinha neste período uma organização territorial específica para atender ao mercado externo, e que, segundo Milton Santos, "tornavam o Brasil um grande arquipélago formado por subespaços" (SANTOS, 2005, p. 29).

Em relação à configuração espacial da rede técnica ferroviária brasileira, observa-se que àquelas linhas pioneiras foram se agregando outras linhas que formaram malhas ferroviárias regionais, sempre direcionadas aos principais portos exportadores, ao longo das últimas décadas do século XIX e ao longo da primeira parte do XX, como afirma Monastirsky (2006).
Nessa dinâmica, observa-se que a economia brasileira, com destaque para a produção cafeeira e ainda distante de uma industrialização capitalista, desenvolveu-se sobremaneira com a introdução da estrada de ferro. Esta foi resultado da combinação das forças entre o capital mercantil nacional, o capital financeiro inglês e o estado brasileiro, ao qual coube oferecer garantia de juros aos investimentos externos em ferrovias, assegurando ao capital estrangeiro rentabilidade certa em longo prazo.

Ainda para o referido autor supracitado:

Com este intuito, nas três últimas décadas do século XIX, governo e pessoas ligadas ao novo regime, influenciados com a reconhecida estratégia da Revolução Francesa e baseando-se na metodologia positivista, organizaram-se na construção e no reconhecimento de símbolos que pudessem referenciar a república brasileira e o novo status quo.

Entre os principais elementos que poderiam se constituir em símbolos para a firmação da ideia republicana estavam as inovações tecnológicas - certamente as responsáveis pelas grandes transformações que o Brasil teria porvir.

Com isso, a ferrovia, uma das mais importantes tecnologias de vanguarda, transformou-se facilmente num símbolo de progresso para o Brasil, pois apresentava características convincentes e inapeláveis: foi praticamente implantada simultaneamente aos países ricos; era considerada um dos principais elementos para o desenvolvimento econômico nacional, dinamizando as exportações e a concentração financeira das atividades voltadas ao transporte; promoveu modificações do espaço urbano das "cidades ferroviárias" com a implantação de equipamentos ferroviários. (MONASTIRSKY, 2006, p. 44).

Esse processo gerou uma série de implicações dentre as quais se pode destacar que viabilizou o surgimento de uma classe trabalhadora privilegiada; possibilitou o transporte rápido, seguro e confortável para carga e pessoas; acelerou os processos de integração regionais e nacional, além disso:

A representatividade da ferrovia como tecnologia de vanguarda, associada à expectativa de desenvolvimento, foi inicialmente incentivada pelo movimento republicano, ampliou-se nas décadas de 1920/30 e se estendeu até meados do século XX, quando 
diminuíram consideravelmente os investimentos de manutenção e modernização da estrutura ferroviária brasileira em função da nova ordem: o transporte rodoviário. (MONASTIRSKY, 2006, p. 48).

Fechando o parêntese, observa-se que a rede urbana pode ser compreendida como um reflexo e condição social, submetida a um dinamismo, maior ou menor e com ritmos variados, de cada formação espacial; a expansão da malha ferroviária no território brasileiro demonstrou tal processo.

Considerando as palavras de Corrêa (2006, p. 311) compreende-se:

A rede urbana, entendida como um conjunto de centros funcionalmente articulados, constitui-se em um reflexo social, resultado de complexos e mutáveis processos engendrados por diversos agentes sociais. Desta complexidade emerge uma variedade de tipos de redes urbanas, variadas de acordo com combinações de características, como o tamanho dos centros, a densidade deles no espaço regional, as funções que desempenham, a natureza, intensidade, periodicidade e alcance espacial das interações e a forma da rede.

Reflexo social, a rede urbana constitui-se, também, como qualquer materialidade social em uma condição; uma das matizes em que é forjada a reprodução da existência social envolvendo as condições de produção, as relações sociais e os traços culturais.

No caso brasileiro, o autor considera a complexidade funcional dos centros urbanos como uma primeira característica, o pequeno grau de articulação entre os centros, definindo um padrão de articulação ainda fortemente marcado por relações regionais, a segunda característica e o padrão espacial com que a rede urbana estava construída, a terceira característica.

Nota-se que, num primeiro momento, se daria uma divisão territorial do trabalho que marcava a vida econômica de grandes áreas do país. $\mathrm{O}$ processo de uma mais efetiva integração nacional ainda estava em seu começo, e as atividades industriais não tinham a expressão que têm, vinculando-se fortemente a mercados regionais; em outras palavras, o País estava estruturado em torno de metrópoles regionais consolidadas ou em formação. Nesse caso, destaca-se o papel da rede ferroviária, cuja importância ainda se fazia sentir na década de 1950.
Diante disso, observa-se que o país se inseriu no processo de globalização e a integração nacional, em decorrência de diferentes fatores, conforme aponta Corrêa (1999), mas para o presente trabalho gostaríamos de destacar: a questão da incorporação de novas áreas e a refuncionalização de outras, dentre as quais destacamos o sul de Mato Grosso, a partir da década de 1970, efetivamente subordinada à economia global, que de áreas tradicionalmente pastoris foram transformadas em áreas agrícolas produtoras, sobretudo de grãos.

Tais transformações traduziram-se em maior complexidade da rede urbana, como é o caso do município de Campo Grande, que se tornou capital do Estado de Mato Grosso do Sul, criado em 1979.

\section{A construção da CEFNOB e a dinâmica do desenvolvimento urbano de Campo Grande, capital do Estado de Mato Grosso do Sul}

Observando-se a importância da ferrovia na trajetória histórica do Estado brasileiro tem-se que, apenas em 1854, no Rio de Janeiro, o Barão de Mauá iniciou efetivamente a construção dos primeiros trilhos rumo à Serra do Mar e, segundo Manfredi Neto (1999), dos antigos caminhos dos índios, que eram perseguidos pelos bandeirantes, edificaramse os primeiros trilhos, como a Estrada de Ferro D. Pedro II, mais tarde denominada Central do Brasil. Prossegue o mesmo autor que em 1860/67 é construída a Estrada de Ferro Santos-Jundiaí São Paulo Railway por ingleses; em 1872 a Paulista; 1875 a Mogiana e, no mesmo ano, a Sorocabana.

Seguindo as considerações de Manfredi Neto (1999, p. 18), desde 1851, iniciaram-se as "primeiras discussões em tomo da necessidade de se criar um meio mais rápido e seguro que ligasse o Estado do Mato Grosso ao Litoral do Brasil, para então se evitar o obrigatório caminho fluvial do Prata e do Paraguai (viagem esta que demorava de 40 a 45 dias)".

Ainda de acordo com o referido autor, com o surgimento da demanda, a partir de diversos fatores econômicos, políticos e de soberania nacional, como a descoberta das Minas de Cuiabá, o incremento do comércio do gado e o surgimento de estabelecimentos no Centro-Oeste, responsáveis pelo abasteci- 
mento das caravanas que tinham como destino as Minas, despertou-se nas autoridades políticas, algum interesse, representado pelo decreto do governo Imperial de 1858, criando uma colônia militar em Avanhandava e outra em ltapura, já próximo a Foz do Rio Tietê.

É somente depois da Guerra do Paraguai (1865 a 1870), quando Mato Grosso é invadido, que o govemo Imperial resolveu tratar do assunto com maior interesse. Com efeito, pelo "decreto Imperial $n^{\circ} 2126$, de 13 de março de 1858, criava-se a Colônia Militar de Avanhandava, e pelo decreto $n^{\circ}$ 2200, de 26 de junho daquele mesmo ano, eram também criados a Colônia Militar e o Estabelecimento de Itapura... " (BARROS, 1957,p.282). Até a construção da Estrada de Ferro Noroeste do Brasil, passaram pelo Porto de Itapura, dezenas de embarcações, que faziam o percurso Piracicaba-ltapura, carregando carga variada, desde o sal grosso para o gado, até armamentos e munições destinados ao pessoal envolvido em conflitos no território mato-grossense. (MANFREDI NETO, 1999, p. 18).

A CEFNOB foi, assim, organizada e instalada em 1904, como uma empresa de capitais mistos, brasileiro e franco-belga, com o propósito de levar a término a estrada, que sairia de Bauru, na época distrito de São Paulo dos Agudos, transpondo o rio Paraná e o rio Urubupungá, sob determinado ponto do rio Paraguai, criando para o Brasil oportunidades para o comércio com o Sudeste Boliviano e Norte Paraguaio, além de facilitar a comunicação do litoral com Mato Grosso; o respaldo legal foi o decreto Federal n. 5349 de 18 de outubro de 1904.

Sobre a escolha dos pontos de ligação da ferrovia, Manfredi Neto (1999, p. 19) assim pondera:

Bauru toma-se, dessa forma, uma espécie de eixo onde irá entroncar a Sorocabana e a Paulista, que não conseguirão realizar seu projeto inicial, e a Noroeste nascida fruto das contradições de interesses que animavam os vários grupos dominantes da época, passa por profundas modificações em seu traçado inicial devendo, daquele momento em diante (1907), estender-se até Corumbá, "a fim de atender melhor ao nosso convênio político com a Bolívia e ao Plano Continental de um FerroCarril do Atlântico ao Pacífico. Ligar-se-ia, assim, o Planalto e portanto, o Porto de Santos aos dois países centrais do Continente Sul-Americano,
Paraguai e Bolívia. Por este traçado, de Bauru a Corumbá e do ramal Ponta-Porã, já posto na maior parte, em execução através de todos os obstáculos, não só integrou na vida Nacional o Estado de Mato-Grosso, como se estabeleceria o mais extenso dreno comercial conforme observações encontradas na obra de Fernando de Azevedo.

Cabe destacar, nesse contexto, que outros fatores contribuíram para que fosse dada cada vez mais ênfase à construção dessa estrada, dentre os quais o antigo interesse de integração do interior aos grandes centros urbanos formados a partir do litoral para, dessa forma, proceder à garantia do domínio do território. Nesse sentido, Manfredi Neto (1999, p. 22) destaca as seguintes motivações e justificativas para a construção dessa estrada:

a) políticamente: visaria ligar o país com a região Meridional e Ocidental do Mato Grosso;

b) militarmente: garantiria a defesa das fronteiras;

c) construção de uma ferrovia Transcontinental, ligando o Atlântico ao Pacífico, com $3954 \mathrm{~km}$ de extensão, sendo 1924 km no Brasil e 1828 km na Bolívia e 202 $\mathrm{km}$ no Chile, o que configuraria o porte do empreendimento;

d) comunicação: criando condições para maior modernidade do transporte;

e) incentivo: ao comércio internacional, pois a ferrovia partiria de São Paulo, transporia o Paraná e o Urubupungá, e se dirigia a um ponto do rio Paraguai, adequado para encaminhar para o Brasil, o comércio dos sudoestes boliviano e paraguaio;

f) intercâmbio: das riquezas e das culturas (estratégias econômica, comercial e de hegemonia).

Conforme esclarece Ghirardello (2002, p. 11-12), "A construção da Companhia Estrada de Ferro Noroeste do Brasil (CEFNOB), em direção ao atual Mato Grosso do Sul, abriu extensa região do Estado de São Paulo, ainda não ocupada sistematicamente pelo homem branco.

Nesse sentido, a CEFNOB viria a ser uma estrada de ferro que parte do Estado de São Paulo com vistas a "abrir" territórios até então considerados como "zona desconhecida habitada por índios" ou "terras devolutas não exploradas", diferentemente de suas predecessoras, que tiveram o papel de acompanhar a produção cafeeira (Figura 1). 


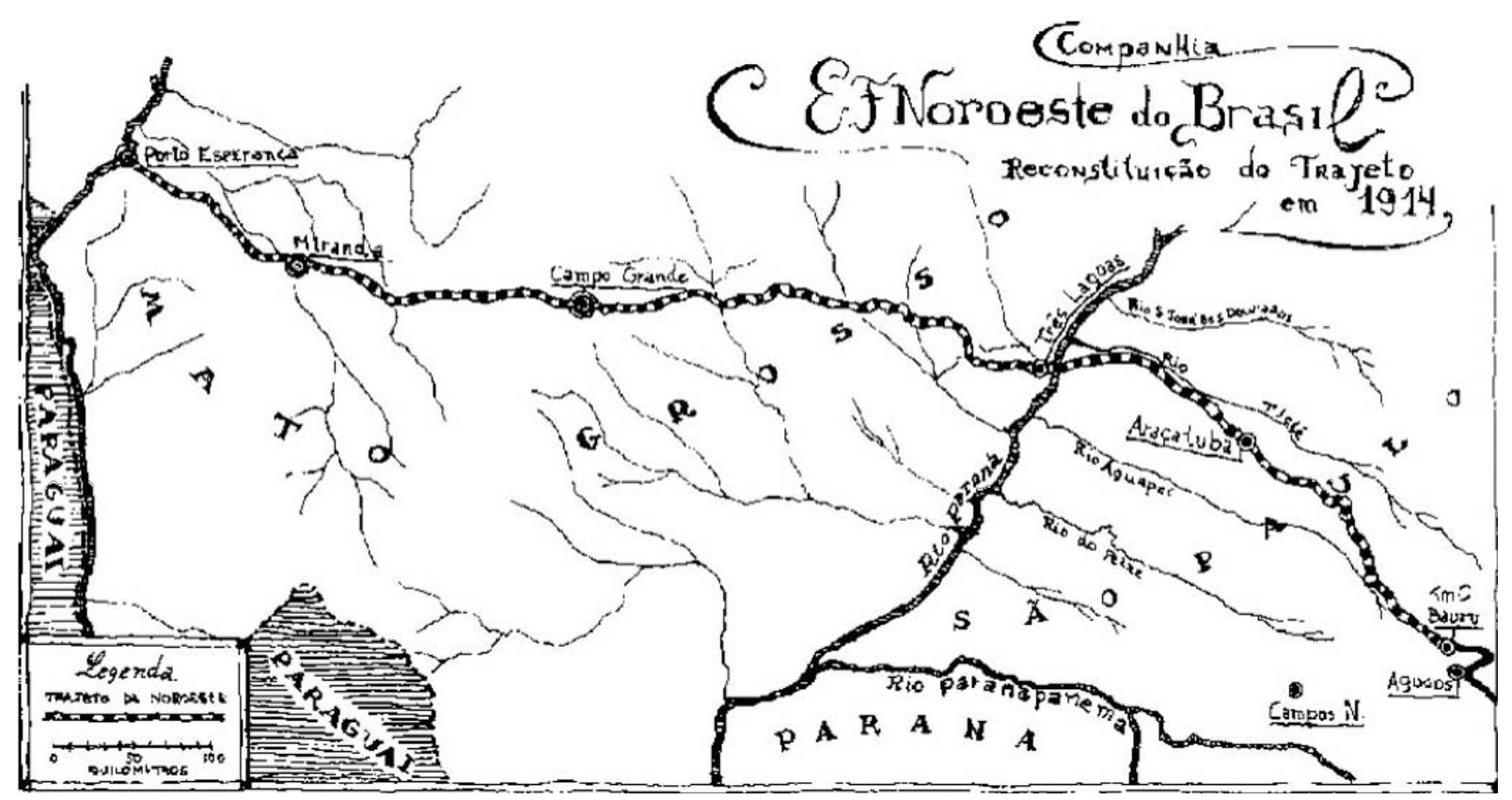

Figura 1 - Percurso da CEFNOB na época de sua inauguração Fonte: Ghiraldello, 2002, p. 14

A construção da CEFNOB iria propiciar a formação de uma importante linha de povoados, depois cidades, estabelecidas a partir de estações, guardando características próprias em relação à origem de seus chãos e à implantação dos traçados urbanos, dentre as quais destacamos Campo Grande, que viria a tornar-se a capital do novo estado-membro da Federação: Mato Grosso do Sul.

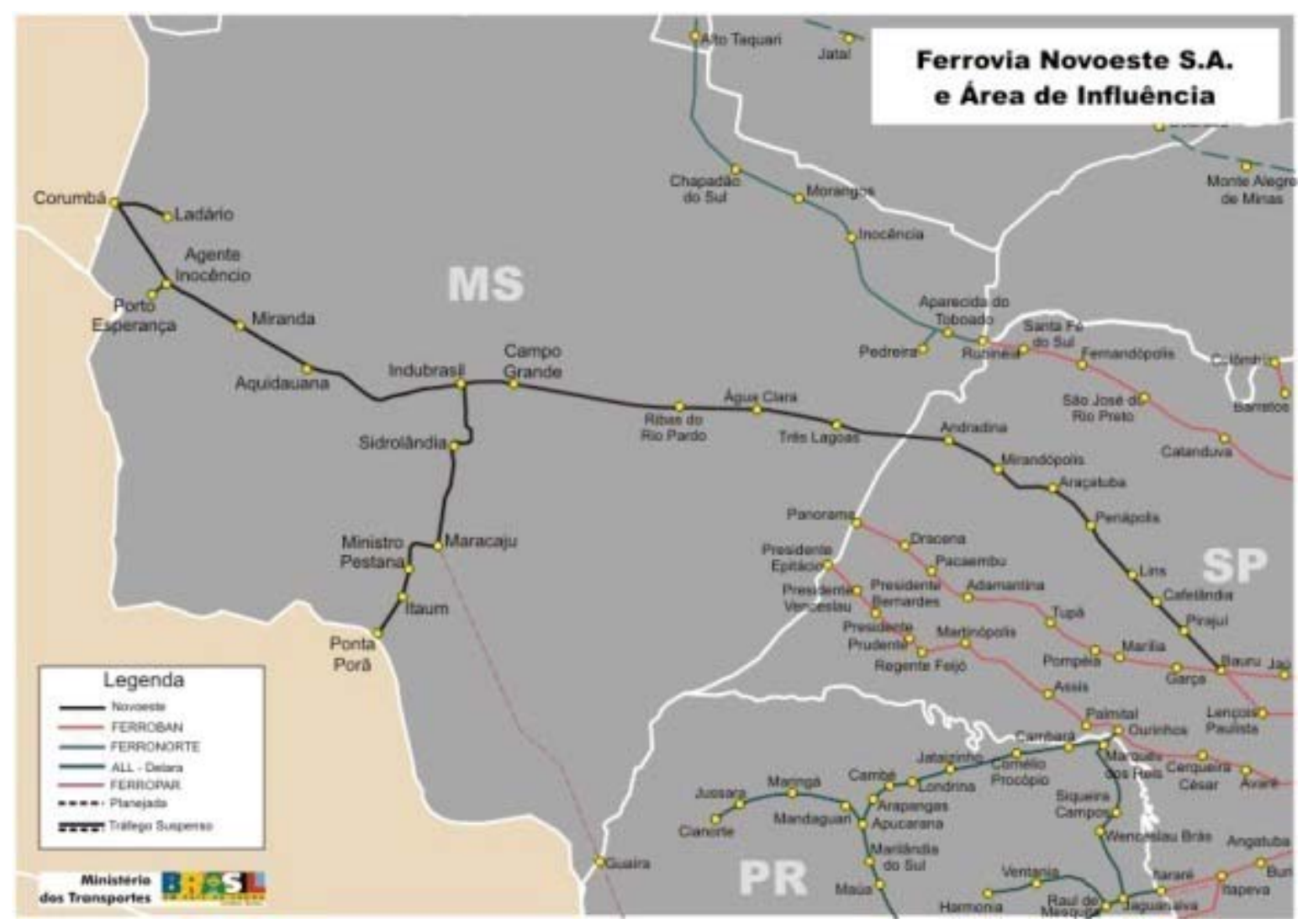

Figura 2 - Área de influência da Ferrovia Novoeste S.A.

Fonte: http:/ / upload.wikimedia.org/wikipedia/commons/0/06/Mapa-Novoeste.jpg (2011). 
A respeito dessa questão buscamos respaldo na obra de Souza (2007, p. 3):

Durante o Estado Novo, e como desdobramento da Marcha para Oeste, foram criados, em 13 de setembro de 1943, o Território Federal de Ponta Porá, e, logo a seguir, em 28 de outubro do mesmo ano, a Colônia Agrícola Nacional de Dourados (CAND). É importante lembrar que na fronteira com o Paraguai, grandes extensões de terras eram monopolizadas pela Companhia Matte Larangeira (1864) que passa a sofrer influências das políticas nacionalistas e reformistas implementadas pelo governo Vargas, dentre elas, o combate aos latifúndios. Cabe ressaltar, que grande parte das terras fronteiriças, consideradas de segurança nacional eram ocupadas pela Companhia, fato este, que somado aos projetos centralizadores de desenvolvimento da região e o cunho nacionalista da política governamental ocasionaram a perda da concessão da Companhia.

Levando-se em consideração as argumentações de Souza (2007), observa-se que a chegada da CEFNOB veio nacionalizar o sul de Mato Grosso. Porém sua divisão enquanto estado-membro da Federação veio concretizar-se apenas no ano de 1979, consagrando-se Campo Grande como sua capital.

Ainda a esse respeito o autor comenta que:

Ao estado de Mato Grosso do Sul, emerso de um contexto político autoritário, havia sido reservado o papel de estado modelo, isto é, um estado onde seriam aplicadas novas técnicas de administração pública. É possível inferir que, o Governo Central via o recémcriado estado como mais um mecanismo de equilíbrio tanto da redemocratização do país quanto realinhamento do capital que urgia após a exaustão do milagre econômico.

Por outro lado, é preciso considerar que as alegadas razões para a divisão do estado podem não ser originárias de apelo popular. O mais provável é que a independência em relação ao norte mato-grossense permitisse às elites locais galgar alguns cargos mais facilmente, ao ter sua capacidade de influência facilitada pela proximidade geográfica com um centro administrativo no sul do estado. (SOUZA, 2007, p. 5).

Campo Grande é por assim dizer, uma cidade que surgiu de uma conexão de ramais ferroviários e se expandiu em várias direções a partir de grandes eixos de circulação. Para a geógrafa Le Bourlegat (2007, p. 26-27):
Houve uma certa mudança em meados de 1980 e início dos anos 1990.Nessa década, a taxa de urbanização de Campo Grande foi a maior do país. Atingimos o maior índice de renda e de carros per capita do Brasil, seguido de uma verticalização muito grande de seu espaço construído nos anos 1990. Com uma renda social média elevada a melhoria no transporte coletivo, começaram algumas reformas urbanas. A construção de vias perimetrais e a integração do transporte coletivo permitiram que vários pontos da cidade pudessem se articular melhor com o centro e entre si. Em meados dos anos de 1990, Campo Grande começou a crescer de acordo com princípios do novo modelo e organização espacial, que chamamos de pós-fordista. Isso foi facilitado pelo esgotamento do modelo de êxodo rural em favor dos deslocamentos populacionais dentro da própria cidade, especialmente quando a administração pública passou a investir na requalificação urbana das áreas periféricas, com apoio da União e de parceiros privados.

A mesma autora, comentando acerca do processo de planejamento público, no município de Campo Grande, considera:

Os projetos de desenvolvimento precisam ter realmente a participação das comunidades. São elas que têm de dizer o que precisam. Não é mais hora da prefeitura ter respostas técnicas para isso. Saímos da era das políticas públicas para as ações políticas compartilhadas. É a coletividade do local quem deve elaborar seu projeto de desenvolvimento com apoio das organizações inclusive da prefeitura. Nesse caso, participar tem o sentido pleno de "fazer parte integral" do processo. O papel da prefeitura é do de agente animador, articulador e representante dos vários territórios da cidade junto aos organismos de apoio e aos financiadores. O planejamento, desse modo, passa a ser um instrumento de controle da sociedade. Não se pode criar um modelo único para Campo Grande, já que cada local tem sua história suas peculiaridades. As pessoas têm necessidades próprias e é com elas que a gente tem que trabalhar. (LE BOURLEGAT, 2007, p. 26-27).

Dessa forma, o presente trabalho procurou destacar a influência do processo de globalização no meio urbano, em particular no dinamismo das cidades. Para tanto, buscamos aplicar alguns conceitos referendados pelos autores citados, a análise do município 
de Campo Grande, capital do estado de Mato Grosso do Sul.

\section{Considerações finais}

Retomando o processo de globalização, percebe-se que ele pode ser compreendido na própria dinâmica do sistema mundial capitalista a partir dos grandes descobrimentos, da revolução industrial e das ondas sucessivas de expansão do capital e sua internacionalização. Porém é mais comumente abordado como um processo de globalização decorrente da crise do padrão Bretton Woods, com a desregulamentação do sistema financeiro internacional, que também impulsionou uma Terceira Revolução Industrial, com uma nova divisão internacional do trabalho, a partir de meados da década de 1970.

Destacando uma das várias facetas da globalização, pode-se dizer que, especialmente após a Segunda Guerra Mundial, ela se manifesta pelo espraiamento do capital produtivo oriundo de grandes corporações e que leva o Estado a atuar como um importante centro de gestão do território, tendo em vista os ciclos de reprodução do capital.

No caso brasileiro, observaram-se, no último quartel do século $X X$, novos núcleos de povoamento em áreas de fronteira de ocupação e fronteira de modernização, onde se caracteriza uma refuncionalização decorrente da combinação de manifestações da globalização, como processos de aceleração das trocas, deslocamento da produção para outras partes do território, acesso às infraestruturas, recriando o papel das cidades no processo de desenvolvimento.

Pode-se dizer que o país se inseriu no processo de globalização e integração nacional, em decorrência de diferentes fatores, dentre os quais: a questão da incorporação de novas áreas e a refuncionalização de outras, dentre as quais o sul de Mato Grosso, a partir da década de 1970, efetivamente subordinada à economia global, que de áreas tradicionalmente pastoris foram transformadas em áreas agrícolas produtoras, sobretudo de grãos. Tais transformações traduziram-se em maior complexidade da rede urbana, como é o caso do município de Campo Grande, que se tornou capital do Estado de Mato Grosso do Sul, criado em 1979.
Assim, observa-se que a construção da CEFNOB pôde propiciar a formação de uma importante linha de povoados, depois cidades, estabelecidas a partir de estações, guardando características próprias em relação à origem de seus chãos e à implantação dos traçados urbanos, dentre as quais destacamos Campo Grande, que viria a tornar-se a capital do novo estado-membro da Federação: Mato Grosso do Sul.

Levando-se em consideração as argumentações de Souza (2007), observa-se que a chegada da CEFNOB veio nacionalizar o sul de Mato Grosso. Porém sua divisão enquanto estado-membro da Federação veio concretizar-se apenas no ano de 1979, consagrando-se Campo Grande como sua capital.

Campo Grande surgiu, portanto, de uma conexão de ramais ferroviários e se expandiu em várias direções a partir de grandes eixos de circulação. Pode-se perceber que, de uma trajetória histórica decorrente do ramal ferroviário da CEFNOB, fez-se emergir uma dinâmica urbana no município que, a partir de 1979, se tornaria a capital do Estado.

Na atualidade, a cidade busca sua inserção em uma perspectiva de planejamento, que incorpore a participação da sociedade e, ao mesmo tempo, atraia novas oportunidades de investimento, como é o caso do Plano Urbanístico de ocupação da Esplanada Ferroviária, que será em breve estudado.

\section{Referências}

CORREAA, Roberto L. Globalização e reestruturação da rede urbana - uma nota sobre as pequenas cidades. In: _. Estudos sobre a rede urbana. Rio de Janeiro: Bertrand Brasil, 2006. p. 255-273.

Reflexões sobre a dinâmica recente da rede urbana brasileira. In:__. Estudos sobre a rede urbana. Rio de Janeiro: Bertrand Brasil, 2006. p. 311-330.

DIAS, L. C. Os sentidos da rede: notas para discussão. DIAS, Leila Christina; SILVEIRA, Rogério Leandro Lima da (Org.). Redes, sociedades e territórios. Santa Cruz do Sul: EDUNISC, 2005. p. 11-28.

GHIRARDELLO, N. À beira da linha: formações urbanas da Noroeste Paulista [online]. São Paulo: Editora UNESP, 2002. 235 p. ISBN 85-7139-392-3. Available from SciELO Books <http:/ / books.scielo.org>.

HARVEY, D. A condição pós-moderna. São Paulo: Loyola, 1992.

LE BOURLEGAT, C. A. Da era das políticas públicas para as ações políticas compartilhadas. Campo Grande: Arquivo Histórico de Campo Grande/Fundação Municipal de Cultura, 2007. (Entrevista). 

urbano no município de Campo Grande, MS

MANFREDI NETO, Pascoal. O imaginário do progresso na noroeste. Economia \& Pesquisa, Araçatuba, v. 1, p. 1726, mar. 1999. Disponível em: <http://www.feata.edu. br/revista_economia\&pesquisa_1.htm>.

MONASTIRSKY, L. B. Ferrovia: patrimônio cultural estudo sobre a ferrovia brasileira a partir da região dos Campos Gerais (PR). 2006. 190f. Tese (Doutorado em Geografia) - Universidade Federal de Santa Catarina, Florianópolis, 2006.

SANTOS, M. A urbanização brasileira. 5. ed. São Paulo: Edusp, 2005.

. A natureza do espaço. São Paulo: Hucitec, 1996.

SILVEIRA, R. L. L. da. Redes e território: uma breve contribuição geográfica ao debate sobre a relação sociedade e tecnologia. Biblio 3W, Revista Bibliográfica de Geografia y Ciencias Sociales, Universidad de Barcelona, v. VIII, $\mathrm{n}$.
451, 15 junio 2003. Disponible en: <http:/ / www.ub.es/ geocrit/b3w-451.htm>. [ISSN 1138-9796]

SOUSA, N. M. et alii. Campo Grande: ano 30 depois da divisão. Ampulheta: revista eletrônica do curso de História, UCDB, Campo Grande, MS, 14 ago. 2007. Disponível em: <http:/ / www.ampulhetta.org/modules.php?na $\mathrm{me}=$ Content $\& \mathrm{pa}=$ showpage $\&$ pid $=41>$.

SOUZA, M. L. Cidades, globalização e determinismo econômico. Cidades: Revistas Científica/Grupo de Estudos Urbanos, Presidente Prudente, SP, v. 3, n. 5, p. 123-142, jan./jun. 2006.

PREFEITURA MUNICIPAL DE CAMPO GRANDE. PLANURB. Plano Urbanístico de ocupação da Esplanada Ferroviária, Campo Grande, 2011. Disponível em: <http:/ / www.capital.ms.gov.br/planurb/ downloads?pg $=2>$. 